\title{
USING LIGHT-AT-NIGHT (LAN) SATELLITE DATA FOR IDENTIFYING CLUSTERS OF ECONOMIC ACTIVITIES IN EUROPE ${ }^{1}$
}

\author{
N. A. Rybnikova ${ }^{\text {a, } * \text {, B. A. Portnov }}{ }^{\text {a }}$ \\ ${ }^{a}$ Dept. of Natural Resources and Environmental Management, Faculty of Management, University of Haifa, Mt. Carmel, 31805, \\ Israel-nrybhiko@campus.haifa.ac.il, portnov@ research.haifa.ac.il
}

KEY WORDS: Economic activities (EAs), clusters, satellite photometry, Light-at-Night (LAN), Europe, Nomenclature of Territorial Units for Statistics (NUTS)

\begin{abstract}
:
Enterprises organized in clusters are often efficient in stimulating urban development, productivity and profit outflows. Identifying clusters of economic activities (EAs) thus becomes an important step in devising regional development policies, aimed at facilitating regional economic development. However, a major problem with cluster identification stems from limited reporting of specific EAs by individual countries and administrative entities. Even Eurostat, which maintains most advances regional databases, provides data for less than $50 \%$ of all regional subdivisions of the $3^{\text {rd }}$ tier of the Nomenclature of Territorial Units for Statistics (NUTS3). Such poor reporting impedes identification of EA clusters and economic forces behind them. In this study, we test a possibility that missing data on geographic concentrations of EAs can be reconstructed using Light-at-Night (LAN) satellite measurements, and that such reconstructed data can then be used for the identification of EA clusters. As we hypothesize, LAN, captured by satellite sensors, is characterized by different intensity, depending on its source - production facilities, services, etc., - and this information can be used for EA identification. The study was carried out in three stages. First, using nighttime satellite images, we determined what types of EAs can be identified, with a sufficient degree of accuracy, by LAN they emit. Second, we calculated multivariate statistical models, linking EAs concentrations with LAN intensities and several locational and development attributes of NUTS3 regions in Europe. Next, using the obtained statistical models, we restored missing data on EAs across NUTS3 regions in Europe and identified clusters of EAs, using spatial analysis tools.
\end{abstract}

\section{INTRODUCTION}

In studies of urban and industrial clustering, the identification of clusters' geographic boundaries is an important research task (Portnov \& Erell, 2001; Cortright, 2006). Commuting patterns are often used for such identification. According to this approach, a cluster is defined as a group of urban settlements or places of employment located within a commuting range of each other (Portnov \& Schwartz, 2009). According to another approach, geographic contiguities of employment, productivity, wages, or population density are used for cluster identification (Cortright, 2006; Desrochers \& Sautet, 2004; Ketels \& Memedovic, 2008). Alternatively, various indices of spatial association (such as, local Moran's $I$ and Geary's $C$ ) can be used for the identification of geographic clusters of economic activities (EAs) (Feser et al., 2001; Kies et al., 2009; Campos \& Prophero, 2012). However, these indices do not perform well if geographically referenced information on neighboring localities is sparse or unavailable (Morgenroth, 2008).

In the past years, Light-at-Night (LAN) data, generated by the U.S. Defense Meteorological Satellite Program (US-DMSP), have been used as a proxy for information on population densities (see inter alia Sutton, 1997; Imhoff et al., 1997; Amaral et al., 2006); economic and technological performance (see inter alia Elvidge et al., 1997; Sutton et al., 2007; Henderson et al., 2009; Ghosh et al., 2009, 2010; Chen \& Nordhaus, 2010; Zhao et al., 2011; Kulkarni et al., 2011;
Mellander et al., 2013), health studies (Kloog et al., 2007, 2009, 2010) (see Ghosh et al., 2013 and Cauwels et al., 2014 for detailed reviews of various LAN-related research applications).

In the present study, we propose and test a two-step approach to the identification of clusters of EAs using LAN satellite images:

First, using freely-available LAN data, we restore missing information on the geographic concentrations of EAs located at EU NUTS3 regions. The underlying assumption behind this approach is that LAN, emitted from geographic concentrations of EAs, is characterized by different intensities, depending on its source - industries, commerce, services, etc. (Rybnikova and Portnov, 2014). As a result, LAN intensities can become a marker for different types of EAs, helping to identify the aerial concentrations of these activities and delineate their geographic clusters. At this stage, we used different concentration indices (such as density of the employed and gross value added) to determine which of them can best be "predicted" by average LAN intensities, and thus to use it to reconstruct data on specific EAs for NUTS3 regions with missing observations.

Second, to identify the geographic clusters of different EAs, we applied to reconstructed data spatial analysis tools, available at ArcGIS software. To this end, we first computed local Moran's $I$ statistic (Anselin, 1995) and applied kriging interpolation to identify areas with highly positive and significant Moran's $I$ values (Z-Moran's $I>1.96$; $\mathrm{P} \leq 0.05$ ). As an alternative cluster identification approach, we applied kriging directly to the restored values of EAs and then selected top 5\% of the

\footnotetext{
1 The paper is based on the article prepared for the Special Issue of Letters in Spatial and Resource Sciences on, "Housing Market, Regional Mobility \& Economic Growth - Dutch-Israeli Workshop".

* Corresponding author
} 
estimated values as the selection threshold for cluster delineation.

Although there are some empirical studies exploring association between LAN levels and aggregated economic sectors (see for instance Doll et al., 2006), to the best of our knowledge, there have been no attempts to use LAN intensities for reconstructing EA data for specific types of EAs and to use these data to identify the geographic clusters of these activities, such as that we attempt in the present study, which methodology and results are discussed below.

\section{DATA AND METHODS}

\subsection{Study area}

In the present study, we use data for Europe, the world's second-smallest continent (after Australia), which land area is about 23.0 million $\mathrm{km}^{2}$ and combined population is about 740 million residents (WA, 2014).

Since the early 1970's, the Eurostat established the Nomenclature of Territorial Units for Statistics (NUTS) used to collect and analyze regional statistical data. According to this nomenclature, all the member states of the EU, EU candidate countries and European Free Trade Association (EFTA) countries (i.e., Iceland, Norway, Principality of Liechtenstein, and Switzerland) are divided into a hierarchical system of NUTS units, ranging from NUTS1, which represent entire countries or regions, to NUTS2 and NUTS3 units, which are concomitant with regions, provinces or sub-regions (EP, 2014b). In the present study, we use the most detailed, NUTS3 classification, formed by 1,315 NUTS 3 regions in the year2010 .

Although data on specific EAs, available from the Eurostat Portal (EP, 2014a), are, apparently, best of this kind in the world, even this, fairly comprehensive, data source is essentially sparse in its geographic coverage. Thus, according to the Eurostat database, out of 1,315 NUTS3 regions in 2010, data on specific EAs are available for about 600 regions only, that is, for less than $50 \%$ of all regional subdivisions.

\subsection{Research variables and data sources}

In order to represent different types of EAs in multivariate analysis, we tested several alternative indices, including density of the employed (persons per $\mathrm{km}^{2}$ ) and gross value added by EA per employee ( $€$ per person); this should help to reveal EAALAN association for EAs with different rates of resources used in their output production. The information on these indices for NUTS3 regions with available EA data were obtained from the Eurostat Portal (EP, 2013).

Data on LAN intensity, used in the analysis as an explanatory variable, were obtained from the U.S. Defense Meteorological Satellite Program (DMSP, 2014). The satellite images, used in our study, were constructed by the DMSP by averaging daily readings of the satellite sensors and removing the cloud cover. The year 2010 satellite images we used in our study are of 750x750-m resolution per pixel and report LAN intensity in dimensionless units, ranging from 0 to about 1,000 . We calculated average LAN levels for individual NUTS 3 regions by applying pixel-by-pixel averaging and using the "zonal statistics" tool in the ArcGIS10. ${ }^{\mathrm{TM}}$ software.
Geographic and socio-economic features of geographic areas are known to contribute to the locational patterns of EAs. For instance, agriculture is often dependent on the latitude, average temperatures and the amount of precipitation (Reidsma et al., 2010), while good roads are needed to facilitate trade (Duranton et al., 2013). Finance, professional and scientific activities are often "tied" to major cities, which are loci of population density and productivity (Henderson, 2010; Cuadrado-Roura \& Rubalcaba-Bermejo, 1998). Due to these considerations, we added the following factors as explanatory variables (in addition to LAN), as regional determinants of EAs' concentrations: latitude (decimal degrees); July and January average temperatures $\left({ }^{\circ} \mathrm{C}\right)$; distances from NUTS3 centroids to the nearest major city, to the seashore, to the main road, to the rail, and to the river $(\mathrm{km})$; population density (persons per $\mathrm{km}^{2}$ ), and gross domestic product ( $€$ per capita); these data were obtained by combining data from the ESRI ArcGIS ${ }^{\mathrm{TM}}$ database (ESRI, 2013) and the Eurostat Portal (EP, 2013), or calculated them in the ArcGIS10.x ${ }^{\mathrm{TM}}$ software.

For descriptive statistics on research variables, see Appendix.

\subsection{Statistical analysis}

In order to determine the relative strength of the factors affecting EAs' variation across NUTS3 units, we used the following generic equation:

$$
E A I_{x z i}=b_{0 x z}+b_{1 x z} \cdot \ln (L A N)_{i}+b_{2 x z} \cdot \boldsymbol{L}+b_{3 x z} \cdot \mathbf{S E}+\varepsilon
$$

where

$E A I_{x z i}=$ value of EAs' index $z$ (i.e., employment density or gross value added), estimated for the $x^{\text {th }} \mathrm{EA}$ in the $i^{\text {th }}$ region;

$b_{0 x z} \ldots b_{3 x z}=$ regression coefficients;

$\ln (L A N)=$ natural logarithm of LAN (dimensionless units);

$\boldsymbol{L}=$ vector of locational attributes of NUTS3 regions, such as latitude (dd); distances to the seashore, to the main road, to the rail, to the river $(\mathrm{km})$; average January and July temperatures $\left({ }^{\circ} \mathrm{C}\right)$;

$\boldsymbol{S} \boldsymbol{E}=$ vector of socio-economic attributes, such as GDP per capita and population density;

$\mathcal{E}=$ random error term.

The models' performance was compared using adjusted $R^{2}$ values as a measure of regression fit. Similarly, to assess the strength of LAN contribution to the observed variation of EAs $v s$. that of other predictors, we applied the $F$-test of $R^{2}$-change, with $F$-values larger than $3.0(\mathrm{P}<0.05)$ being considered as a statistically significant improvement.

During the analysis, the Kolmogorov-Smirnov/Lillifors normality test was performed. Since we detected deviations from normality for several dependent variables, a Box-Cox transformation was applied to the original values of the dependent variables with significant deviations from normality. 


\section{RESEARCH RESULTS}

\subsection{EA predictions}

Tables 1-3 report OLS models for specific types of EAs, for which especially good explanatory power of the models could be obtained $\left(\mathrm{R}^{2}-a d j .>0.8\right)$; these are 3 of 11 reported by Eurostat Portal EAs, viz: "Professional, scientific and technical activities; administrative and support service activities" (Table 1); "Public administration, defense, compulsory social security; education; human health and social work activities" (Table 2); and "Arts, entertainment and recreation; other service activities; activities of households as employers; activities of extra-territorial organizations and bodies" (Table 3). As Tables 1-3 show, the models reported help to explain up to $90 \%$ of the EA variation, performing especially well for professional \& scientific activities $\left(\mathrm{R}^{2}\right.$-adj. $\left.=0.901, \mathrm{~F}=702.976 ; \mathrm{P}<0.001\right)$.

\begin{tabular}{|c|c|c|}
\hline \multirow{2}{*}{ Variable } & \multicolumn{2}{|c|}{ Professional activities ${ }^{\mathrm{e}}$} \\
\hline & $\mathrm{B}^{\mathrm{a}}$ & $\mathrm{t}^{\mathrm{b}}$ \\
\hline (Constant) & -3.499 & $-8.720 * * *$ \\
\hline $\operatorname{Ln}(\mathrm{LAN})$ & 1.159 & $40.432 * * *$ \\
\hline Latitude (dd) & -0.012 & $-1.990 * *$ \\
\hline D_seashore $(\mathrm{km})$ & 0.001 & $3.969 * * *$ \\
\hline D_mroads (km) & 0.002 & $4.106 * * *$ \\
\hline D_city $(\mathrm{km})$ & -0.001 & $-3.355^{* * *}$ \\
\hline D_rivers (km) & -0.001 & $-13.176^{* * * *}$ \\
\hline $\mathrm{T}_{\mathrm{Jan}}\left({ }^{\circ} \mathrm{C}\right)$ & 0.114 & $10.453 * * *$ \\
\hline $\operatorname{Ln}(G D P p c)(€)$ & 0.195 & $4.820 * * *$ \\
\hline $\begin{array}{l}\text { Population } \\
\text { density } \\
\left(\text { per } \mathrm{km}^{2}\right)\end{array}$ & $1.38 \mathrm{E}-04$ & $3.977 * * *$ \\
\hline $\mathrm{N}$ of obs. & \multicolumn{2}{|c|}{707} \\
\hline $\mathrm{R}^{2}$ & \multicolumn{2}{|c|}{0.901} \\
\hline Adjusted $\mathrm{R}^{2}$ & \multicolumn{2}{|c|}{0.899} \\
\hline $\mathrm{F}$ & \multicolumn{2}{|c|}{$702.976 * * *$} \\
\hline $\mathrm{SEE}^{\mathrm{c}}$ & \multicolumn{2}{|c|}{0.540} \\
\hline
\end{tabular}

Table 1. Factors affecting the density of employed in professional activities (persons per $\mathrm{km}^{2}$ )

Notes: *,** and *** indicates a $0.1,0.05$ and 0.01 significance levels. ${ }^{\text {a }}$ Unstandardized regression coefficient; ${ }^{\mathrm{b}} t$-statistic; ${ }^{\mathrm{c}}$ Standard error of the estimate; $d d=$ decimal degrees. ${ }^{\mathbf{e}}$ Data transformed using the BoxCox transformation procedure (see Appendix).

\begin{tabular}{|c|c|c|}
\hline \multirow[t]{2}{*}{ Variable } & \multicolumn{2}{|c|}{$\begin{array}{c}\text { Public } \\
\text { administration }^{\mathrm{e}}\end{array}$} \\
\hline & $\mathrm{B}^{\mathrm{a}}$ & $\mathrm{t}^{\mathrm{b}}$ \\
\hline (Constant) & 0.067 & 0.295 \\
\hline $\operatorname{Ln}(\mathrm{LAN})$ & 0.794 & $55.654 * * *$ \\
\hline Latitude (dd) & 0.013 & $3.679 * * *$ \\
\hline D_seashore $(\mathrm{km})$ & 0.001 & $7.199 * * *$ \\
\hline D_mroads (km) & 0.001 & $2.267 * *$ \\
\hline D_rivers (km) & -0.001 & $-11.478 * * *$ \\
\hline $\mathrm{T}_{\mathrm{Jan}}\left({ }^{\mathrm{o}} \mathrm{C}\right)$ & 0.103 & $16.296 * * *$ \\
\hline $\operatorname{Ln}(\mathrm{GDPpc})(€)$ & -0.130 & $-5.868 * * *$ \\
\hline $\begin{array}{l}\text { Population } \\
\text { density } \\
\left(\text { per } \mathrm{km}^{2}\right)\end{array}$ & 4.18E-05 & $2.995 * * *$ \\
\hline $\mathrm{N}$ of obs. & \multicolumn{2}{|c|}{803} \\
\hline $\mathrm{R}^{2}$ & \multicolumn{2}{|c|}{0.899} \\
\hline Adjusted $\mathrm{R}^{2}$ & \multicolumn{2}{|c|}{0.898} \\
\hline
\end{tabular}
$\mathrm{F}$
$879.672 * * *$
$\mathrm{SEE}^{\mathrm{c}}$
0.329

Table 2. Factors affecting the density of employed in public administration (persons per $\mathrm{km}^{2}$ )

Note: see footnote to Table 1

In these models, LAN emerged with the expected sign, indicating that densities of the employed in these activities across NUTS3 regions tend to increase with LAN intensities, being especially strong for public administration $(\mathrm{t}>55.0$; $\mathrm{P}<0.001$; see Table 2).

\begin{tabular}{|c|c|c|}
\hline \multirow{2}{*}{ Variable } & \multicolumn{2}{|c|}{ Arts \& entertainment ${ }^{\mathrm{e}}$} \\
\hline & $\mathrm{B}^{\mathrm{a}}$ & $\mathrm{t}^{\mathrm{b}}$ \\
\hline (Constant) & -4.396 & $-8.972 * * *$ \\
\hline $\operatorname{Ln}(\mathrm{LAN})$ & 1.055 & $37.036 * * *$ \\
\hline D_seashore $(\mathrm{km})$ & 0.001 & $4.134 * * *$ \\
\hline D_mroads (km) & 0.003 & $2.475 * *$ \\
\hline D_rail (km) & -0.001 & $-1.873 *$ \\
\hline D_rivers $(\mathrm{km})$ & -0.001 & $-7.371 * * *$ \\
\hline $\mathrm{T}_{\text {July }}\left({ }^{\circ} \mathrm{C}\right)$ & 0.034 & $4.415^{* * * *}$ \\
\hline $\mathrm{T}_{\mathrm{Jan}}\left({ }^{\circ} \mathrm{C}\right)$ & 0.134 & $15.260 * * *$ \\
\hline $\operatorname{Ln}(G D P p c)(€)$ & 0.113 & $2.639 * * *$ \\
\hline $\begin{array}{l}\text { Population } \\
\text { density } \\
\left(\text { per } \mathrm{km}^{2}\right)\end{array}$ & 2.49E-04 & $6.930 * * *$ \\
\hline $\mathrm{N}$ of obs. & \multicolumn{2}{|c|}{707} \\
\hline $\mathrm{R}^{2}$ & \multicolumn{2}{|c|}{0.880} \\
\hline Adjusted $\mathrm{R}^{2}$ & \multicolumn{2}{|c|}{0.879} \\
\hline $\mathrm{F}$ & \multicolumn{2}{|c|}{$568.693^{* * *}$} \\
\hline $\mathrm{SEE}^{\mathrm{c}}$ & \multicolumn{2}{|c|}{0.558} \\
\hline
\end{tabular}

Table 3. Factors affecting the density of employed in arts \& entertainment (persons per $\mathrm{km}^{2}$ ) Note: see footnote to Table 1

3.1.1 Assessing OLS models: In the reported models, LAN appears to be a strong positive predictor for the EAs analyzed, contributing to about $40 \%$ of the explained variance in addition to all the other predictors (see Table 4)

\begin{tabular}{lcccc}
\hline \multicolumn{1}{c}{$\begin{array}{c}\text { Prediction } \\
\text { model } \\
\text { (Tables 1-3) }\end{array}$} & $\begin{array}{c}\mathrm{R}^{2} \text { change } \\
\text { attributed to } \\
\text { LAN inclusion }\end{array}$ & $\begin{array}{c}\mathrm{R}^{2} \text { change } \\
\text { attributed to } \\
\text { the inclusion of } \\
\text { all other predictors }\end{array}$ \\
\cline { 2 - 5 } & $\begin{array}{c}\mathrm{R}^{2}- \\
\text { change }\end{array}$ & $F$-statistic & $\begin{array}{c}\mathrm{R}^{2}- \\
\text { change }\end{array}$ & $\begin{array}{c}F- \\
\text { statistic }\end{array}$ \\
\hline $\begin{array}{l}\text { Professional } \\
\text { activities }\end{array}$ & 0.233 & $1634.749 * * *$ & 0.076 & $66.633 * * *$ \\
$\begin{array}{l}\text { Public } \\
\text { administration } \\
\begin{array}{l}\text { Arts \& } \\
\text { entertainment }\end{array}\end{array}$ & 0.396 & $3097.387 * * *$ & 0.080 & $89.661 * * *$ \\
\hline
\end{tabular}

Table 4. F-test of $R^{2}$-change for different prediction models Note: *** Indicates a 0.001 two-tailed significance level

Although the estimated values of EAs in the NUTS3 regions demonstrated highly significant correlations $(r>0.6 ; \mathrm{p}<0.05)$, models estimated for individual types of EAs are activityspecific, not generic, as our analysis demonstrates (see Table 5). In particular, as this table shows, standard errors of the estimates are significantly lower in the models estimated for specific types of EAs than those in the models estimated for one type of EA and applied to another. 


\begin{tabular}{lccc}
\hline \multicolumn{1}{c}{ Predicted EAs } & $\begin{array}{c}\text { Model for } \\
(1)\end{array}$ & $\begin{array}{c}\text { Model for } \\
(2)\end{array}$ & $\begin{array}{c}\text { Model for } \\
(3)\end{array}$ \\
\hline $\begin{array}{l}\text { (1) Professional } \\
\text { activities }\end{array}$ & 0.540 & $1.275 * * *$ & $0.715^{* * *}$ \\
$\begin{array}{l}\text { (2) Public } \\
\text { administration }\end{array}$ & $1.187 * * *$ & 0.329 & $1.435 * * *$ \\
$\begin{array}{l}\text { (3) Arts \& } \\
\text { entertainment }\end{array}$ & $0.719 * * *$ & $1.519 * * *$ & 0.558 \\
\hline
\end{tabular}

Table 5. Standard errors of the estimates for different prediction models

Note: *** Indicates that probabilities of similarities for both means and medians (computed for $t$-test and Wilcoxon test correspondingly) between series of residuals (obtained as differences between actual EAs values and their estimates via different prediction models) are too low (e.g. $<<0.001)$

3.1.2 Model cross-validation: To determine whether our model estimates are sufficiently accurate and can be used for forecasting, we selected a random sample of about $10 \%$ of cases, estimated the models anew based on the rest of the $90 \%$ observations, and calculated the model predictions for the control cases. Then, we applied the $t$-test to determine whether there are statistically significant differences between actually observed values in the "control" subset of regions and our model estimates. The results of the test are reported in Table 6, which shows that the mean differences from zero are statistically insignificant in all the models $(\mathrm{P}>0.51)$, thus indicating that our models are essentially robust.

\begin{tabular}{lccccc}
\hline Type of EA & $\begin{array}{c}\text { N of } \\
\text { obs. }\end{array}$ & $\begin{array}{c}\text { Mean } \\
\text { difference }\end{array}$ & Std. Dev & t & $\begin{array}{c}\text { Sig. (2- } \\
\text { tailed) }\end{array}$ \\
\hline $\begin{array}{l}\text { Professional } \\
\text { activities }\end{array}$ & 76 & -0.007 & 0.502 & -0.081 & 0.936 \\
$\begin{array}{l}\text { Public } \\
\text { administration }\end{array}$ & 81 & -0.025 & 0.345 & -0.495 & 0.622 \\
$\begin{array}{l}\text { Arts \& } \\
\text { entertainment }\end{array}$ & 76 & -0.063 & 0.589 & -0.659 & 0.513 \\
\hline
\end{tabular}

Table 6. $t$-test for differences in the regression models' residuals

(Test value - difference from zero; see text for explanations)

Note: The regression residuals are tested for the statistical significance of differences between the predicted and observed values. The procedure of "Select cases" in SPSS software was performed, random sample of approximately $10 \%$ cases was selected

\subsection{Mapping clusters of EAs}

We used the models reported in Tables 1-3 to reconstruct densities of EAs for NUTS3 regions with missing data. For brevity's sake, we report here the calculations, performed for only one type of EA - for professional activities (see Table 1). The available from Eurostat Portal and reconstructed EA data are shown in Fig. 1.
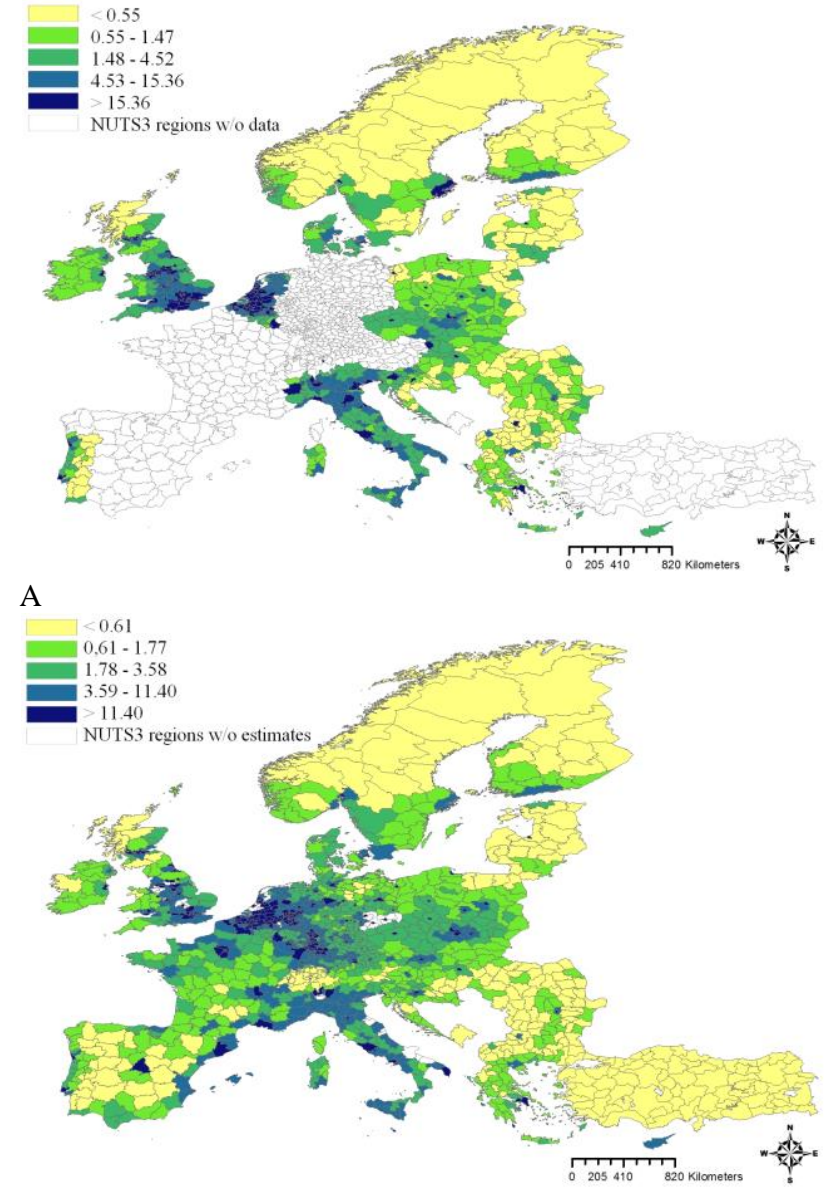

B

Figure 1. Density of employed in professional activities (persons per $\mathrm{km}^{2}$ ): A - Data available for 2010; B - Predicted values

Notes: Both available and estimated values are grouped into five classes using the quintile method

Hence clusters are characterized, according to our operational definition, by high concentrations of EAs and similarity of neighbouring observations, we carried out our analysis in several steps. First, we identified standing-out concentrations of EAs using the reconstructed data on their geographic concentrations, and by setting a top 5\% concentration criterion. Second, we applied the Local Moran's $I$ statistic to the reconstructed EA maps, aiming to identify regions being similar in terms of EAs' densities.

Geographic boundaries of EAs' clusters may be sensitive to the choice of territorial units, reflecting the well-known modifiable aerial unit problem or MAUP (Openshaw, 1984; Portnov, 2012; Jacobs-Crisioni et al., 2014). Therefore, we applied kriging interpolation to identify clusters' boundaries more precisely.

In particular, kriging smoothing was applied to both reconstructed values of EAs, using the above mentioned top 5\% concentration criterion, and to the observed local Moran's $I$ values, using only positive and statistically significant values of this index (Z-Moran's $I>1.96 ; \mathrm{P} \leq 0.05$ ) for cluster identification. The results of both identification approaches appear to be similar, as the outcome maps featured in Figs. $2 \& 3$ demonstrate. 


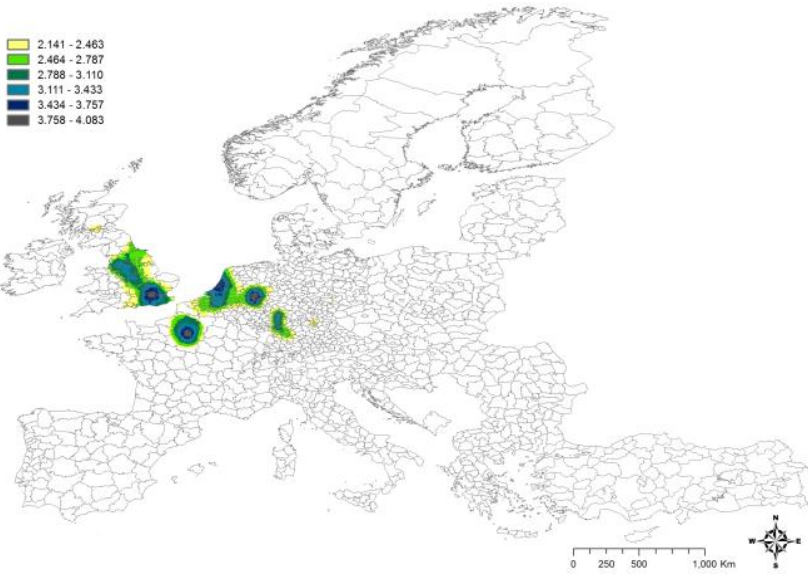

Figure 2. Clusters of professional activities, identified by kriging with subsequent application of the top $5 \%$ concentration criterion

Notes: The color scales are based on the normalized values of densities of the employed in EA, reconstructed using Models in Table 1. Higher values on all scales signify higher concentrations, while lower values mark lower concentrations of EAs in the area

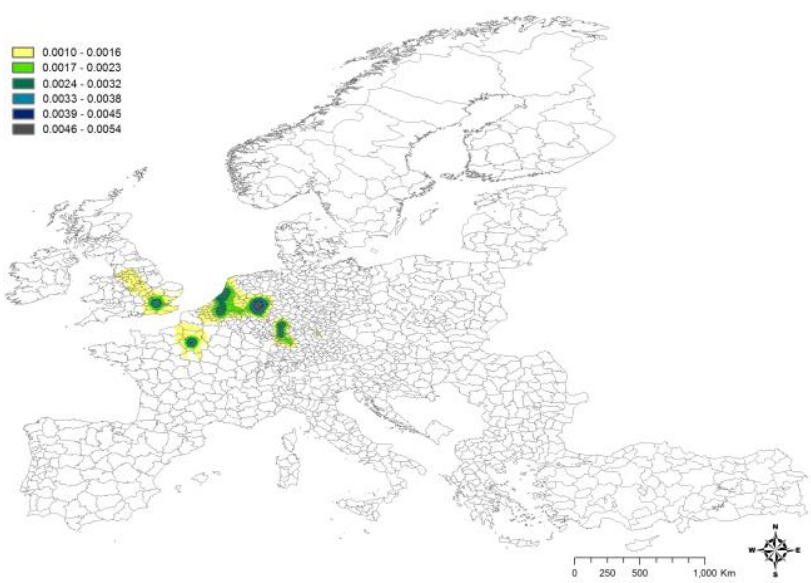

Figure 6. Clusters of professional activities, identified by combination of kriging and high positive values of local Moran's $I$ index

Notes: Color scales are based on local Moran's I values, calculated for the density of the employed in a given EA

\section{CONCLUSIONS}

Clusters of EAs are an important research subject in economic geography. According to previous studies (Porter, 2000; Desrochers \& Sautet, 2004; Cortright, 2006; Ketels \& Memedovic, 2008), such clusters can create appropriate conditions for further development, helping to formulate policy tools and capitalize on such positive effects. However, a major problem with clusters' identification often stems for the scarcity of data about specific EAs, attributed to limited reporting by individual countries and administrative entities.

In the present study we propose and empirically test a research approach which helps to reconstruct missing data on specific EAs, using readily available and/or easily calculated data on LAN intensities, as well as other general attributes of geographic areas (such as, GDP per capita, population density, and various geographical characteristics of the area - latitude, temperatures, distances to the nearest major city, etc.). According to our models, LAN, in combination with other readily available (or easy-to-calculate) data helps to explain up to $90 \%$ of the EA variation, performing especially well for professional activities, public administration and arts \& entertainment. Moreover, in all models we estimated LAN appeared to be the strongest predictor for several types of EAs, with its inclusion into the models helping to explain up to $40 \%$ of EAs variations, being unexplained by other predictors.

The idea to use LAN as a marker for specific EAs is a novel one, used in the present study, to the best of our knowledge, for the first time. The logic beyond this idea is relatively straightforward: LAN, captured by satellite sensors, is likely to differ by intensity, depending on its source, viz., industrial concentrations, agriculture, services, etc.; as a result, LAN levels can become a marker for specific EAs, helping to distinguish between different types of EAs on the ground.

Generally speaking, LAN cannot be viewed as a predictor for EAs per se, because LAN is determined by EAs' concentrations. However, LAN intensities do appear to differ across different types of EAs, thus helping to differentiate between them. The analysis of subset of control cases for models' verification indicated that our estimates are essentially robust, and that the LAN variable can help to differentiate between specific types of EAs on the ground and thus compete, with sufficiently accuracy, missing observations.

To the best of our knowledge, there are only a handful of studies, attempting to assess the association between economic performance and LAN levels (Ebener et al., 2005; Doll et al., 2006; Bhandari \& Roychowdhury, 2011; Xiangdi et al., 2012). However, unlike the present analysis, these studies focused on aggregated economic sectors only.

In the present study, we followed the general suggestion by Ebener et al. (2005) and Bhandari \& Roychowdhury (2011) that EAs' variation can successfully be explained by LAN. However, we advance this idea by using the most precise classification of EAs, available for the EU countries, and tested alternative indices to estimate these activities concentrations in the NUTS3 regions, such as, density of the employed in the activity, GVA per employed in the activity, and corresponding location quotients, which has not been done before. We took the analysis even further and used LAN-reconstructed EAs' data for the identification of geographic clusters of specific types of EAs using spatial analysis tools.

Several limitations of the study need to be mentioned. EAs' predictors may influence (or be influenced by) the others. For instance, LAN, emitted by geographic concentrations of EAs, may be affected by population density and/or proximity to the nearest major city. In our analysis, we tried to address this issue by checking the predictors' multi-collinearity and removing from the models predictors with high variance inflation. NUTS3 regions may also differ in size, and reported (or reconstructed data) on EAs may produce relatively coarse delineations of EAs' clusters. While we used NUTS3 regions, due to unavailability of data for smaller geographic units, and then applied kriging for improving the results, future studies should attempt to identify EAs' clusters more precisely, using, e.g., municipality level data or information on individual enterprises and facilities. This approach can also help to resolve another potential problem, namely insufficiently detailed EAs' classification available for NUTS3 regional units. 
In our view, follow-up studies should be based on geographic units of finer resolution, available for individual countries or regions, helping to confirm the potential of usefulness of LAN for identification of EAs in finer spatial units. It is also important to mention that LAN, emitted from on-ground EAs' concentrations differs not only by intensity, which was analyzed in the present study, but also by spectral properties, accounting for which may further improve the accuracy of EAs' identification results and delineating their geographic clusters.

\section{REFERENCES}

Amaral, S., Monteiro, V., Camara, G., Quintanilha, J.A., 2006. DMSP/OLS night-time light imagery for urban population estimates in the Brazilian Amazon. International Journal of Remote Sensing, 27(5), pp. 855-870.

Anselin, L., 1995. Local indicators of spatial association LISA. Geographical Analysis, 27, pp. 93-115.

Bhandari, L., \& Roychowdhury, K., 2011. Night lights and economic activity in India: A study using DMSP-OLS night time images. Proceedings of the Asia-Pacific Advanced Network, 32, pp. 218-236.

Campos, C., Prothero, R., 2012. The Spatial Distribution of Industries http://www.ons.gov.uk/ons/rel/regionaltrends/regional-economic-analysis/the-spatial-distribution-ofindustries/art-the-spatial-distribution-of-industries.html Apr. 2014).

Cauwels, P., Pestalozzi, N., Sornette, D., 2014. Dynamics and spatial distribution of global nighttime lights http://www.epjdatascience.com/content/3/1/2 (17 Mar. 2014).

Chen, X., \& Nordhaus, W.D., 2010. The value of luminosity data as a proxy for economic statistics. NBER Working Paper http://www.nber.org/papers/w16317 (17 Mar. 2014).

Cortright, J., 2006. Making sense of clusters: regional competitiveness and economic development. Washington, DC: The Brookings Institution.

Cuadrado-Roura, J.R., Rubalcaba-Bermejo, L., 1998. Specialization and Competition amongst European Cities: A New Approach through Fair and Exhibition Activities. Regional studies, 32(2), pp. 133-147.

Defence meteorological satellite program (DMSP), 2014. DMSP nighttime lights data http://ngdc.noaa.gov/eog/ (13 Jan. 2014).

Desrochers, P., \& Sautet, F., 2004. Cluster-based economic strategy, facilitation policy and the market process. The Review of Austrian Economics, 17(2/3), pp. 233-245.

Doll, C.N.H., Muller, J.P., Morley, J.G., 2006. Mapping regional economic activity from night-time light satellite imagery. Ecological Economics, 57(1), pp. 75-92.

Duranton, G., Morrow, P., Turner, M., 2013. Roads and Trade: Evidence from the US http://ssrn.com/abstract=2235491 (17 Apr. 2014).

Ebener, S., Murray, C., Tandon, A., Elvidge, C.D., 2005. From wealth to health: modeling the distribution of income per capita at the subnational level using nighttime light imagery http://www.ij-healthgeographics.com/content/4/1/5 (15 Feb. 2014).

Economic and Social Research Institute (ESRI), 2013. ESRI GeoDatabase http://www.esri.com/software/arcgis/geodatabase (1 Dec. 2013).

Elvidge, C., Baugh, K., Kihn, E., Kroehl, H., Davis, E., Davis, C., 1997. Relation between satellite observed visible-near infrared emissions, population, economic activity and electric power consumption. International Journal of Remote Sensing, 18, pp. 1373-1379.

Eurostat Portal (EP), 2013. Statistical Databases http://epp.eurostat.ec.europa.eu/portal/page/portal/statistics/sear ch_database (1 Dec. 2013)).

Eurostat Portal (EP), 2014a. Geographical information: Administrative units / Statistical units http://epp.eurostat.ec.europa.eu/portal/page/portal/gisco_Geogr aphical_information_maps/popups/references/administrative_un its_statistical_units_1 (15 Feb. 2014).

Eurostat Portal (EP), 2014b. History of NUTS http://epp.eurostat.ec.europa.eu/portal/page/portal/nuts_nomenc lature/documents (13 Jan. 2014).

Feser, E.J., Koo, K., Renski, H.S., Sweeney, S.H., 2001. Incorporating Spatial Analysis in Applied Industry Cluster Studies. Chapel Hill: University of North Carolina.

Jacobs-Crisioni, C., Rietveld, P., Koome, E., 2014. The impact of spatial aggregation on urban development analyses. Applied Geography, 47, pp. 46-56.

Ghosh, T., Anderson, S., Powell, R.L., Sutton, P.C., Elvidge, C.D., 2009. Estimation of Mexico's informal economy and remittances using nighttime imagery. Remote Sensing, 1(3), pp. 418-444.

Ghosh, T., Anderson, S.J., Elvidge, C.D., Sutton, P.C., 2013. Using nighttime satellite imagery as a proxy measure of human well-being. Sustainability, 5(12), pp. 4988-5019.

Henderson, J.V., 2010. Cities and development. Journal of Regional Science, 50(1), pp. 515-540.

Henderson, J.V., Storeygard, A., Weil, D.N., 2009. Measuring economic growth from outer space http://www.nber.org/papers/w15199 (17 Mar. 2014).

Imhoff, M.L., Lawrence, W.T., Stutzer, D.C., Elvidge, C.D., 1997. A technique for using composite DMSP/OLS city lights satellite data to map urban area. Remote Sensing of Environment, 61(3), pp. 361-370.

Ketels, C., \& Memedovic, O., 2008. From clusters to clusterbased economic development. International Journal of Technological Learning, Innovation and Development, 1(3), pp. 375-392.

Kies, U., Mrosek, T., Schulte, A., 2009. Spatial analysis of regional industrial clusters in the German forest sector. International Forestry Review, 11(1), pp. 38-51.

Kloog, I., Haim, A., Stevens, R.G., Barchana, M., Portnov, B.A., 2007. Light at night co-distributes with incident breast but 
not lung cancer in the female population of Israel. Chronobiology International, 25(1), pp. 65-81.

Kloog, I., Haim, A., Stevens, R.G., Portnov, B.A., 2009. Global co-distribution of light at night (LAN) and cancers of prostate, colon, and lung in men. Chronobiology International, 26(1), pp. 108-125.

Kloog, I., Stevens, R.G., Haim, A., Portnov, B.A., 2010. Nighttime light level co-distributes with breast cancer incidence worldwide. Cancer Causes Control, 21, pp. 2059-2068.

Kulkarni, R., Haynes, K., Stough, R., Riggle, J., 2011. Light based growth indicator: exploratory analysis of developing a proxy for local economic growth based on night lights. Regional Science Policy and Practice, 3(2), pp. 101-113.

Mellander, S., Stolarick, K., Matheson, Z., Lobo, J., 2013. Night-Time Light Data: A Good Proxy Measure for Economic Activity? CESIS Electronic Working Paper Series http://www.kth.se/dokument/itm/cesis/cesiswp315.pdf (15 Feb. 2014).

Morgenroth, E., 2008. Exploring the Economic Geography of Ireland. ESRI: Working Paper No. 271 ww.tara.tcd.ie/bitstream/2262/27926/1/WP271.pdf (17 Apr., 2014).

Openshaw, S., 1984. The modifiable areal unit problem. In: Concepts and Techniques in Modern Geography, Monograph Series \#38. Geo Books: London, 41 pp.

Porter, M., 2000. Location, competition, and economic development: local clusters in a global economy. Economic Development Quarterly, 14(1), pp. 15-20.

Portnov, B.A., 2012. Does the choice of geographic units matter for the validation of Gibrat's law? Region \& Development, 36, pp. 79-106.

Portnov, B.A., \& Erell, E., 2001. Urban Clustering: The Benefits and Drawbacks of Location. Ashgate, Aldershot.

Portnov, B., \& Schwartz, M., 2009. Urban clusters as growth foci. Journal of Regional Science, 49(2), pp. 287-310.

Reidsma, P., Ewert, F., Lansink, A.O., Leemans, R., 2010. Adaptation to climate change and climate variability in European agriculture: The importance of farm level responses. European Journal of Agronomy, 32(1), pp. 91-102.

Rybnikova, N.A., \& Portnov, B.A., 2014. Mapping geographical concentrations of economic activities in Europe using light at night (LAN) satellite data. International Journal of Remote Sensing, 35(22), pp. 7706-7725.

Sutton, P., 1997. Modeling population density with night-time satellite imagery and GIS. Computers, Environment and Urban Systems, 21(3/4), pp. 227-244.

Sutton, P.C., Elvidge, C.D., Ghosh, T., 2007. Estimation of gross domestic product at sub-national scales using nighttime satellite imagery. International Journal of Ecological Economics \& Statistics, 8, pp. 5-21.

World Atlas (WA), 2014. Worldatlas: Continents http://www.worldatlas.com/aatlas/infopage/contnent.htm (15 Feb. 2014).
Xiangdi, H., Yi, Z., Shixin, W., Ryu, L., Yao, Y., 2012. GDP spatialization in China based on nighttime imagery. Geoinformation Science, 14, pp. 128-136.

Zhao, N., Currit, N., Samson, E., 2011. Net primary production and gross domestic product in China derived from satellite imagery. Ecological Economics, 70(5), pp. 921-928.

\section{APPENDIX}

\begin{tabular}{|c|c|c|c|c|c|}
\hline Variable & $\begin{array}{l}\mathrm{N} \text { of } \\
\text { obs. }\end{array}$ & Min & Max & Mean & $\begin{array}{l}\text { Std. } \\
\text { Dev. }\end{array}$ \\
\hline $\operatorname{Ln}(\mathrm{LAN})$ & 1453 & -1.76 & 6.22 & 2.72 & 1.12 \\
\hline Latitude (dd) & 1453 & -21.14 & 69.56 & 48.15 & 6.37 \\
\hline D_seashore $(\mathrm{km})$ & 1453 & 0.11 & 6234.56 & 133.91 & 269.65 \\
\hline D_mroads (km) & 1453 & 0.004 & 5992.49 & 20.85 & 277.73 \\
\hline D_rail (km) & 1453 & 0.001 & 6225.91 & 32.82 & 335.73 \\
\hline D_city (km) & 1453 & 0.70 & 6329.41 & 136.06 & 341.66 \\
\hline D_rivers (km) & 1453 & 0.10 & 2689.74 & 287.00 & 329.90 \\
\hline $\mathrm{T}_{\text {July }}\left({ }^{\circ} \mathrm{C}\right)$ & 1453 & 7.50 & 36.00 & 18.86 & 3.92 \\
\hline $\mathrm{T}_{\mathrm{Jan}}\left({ }^{\mathrm{O}} \mathrm{C}\right)$ & 1453 & -11.50 & 18.00 & 2.71 & 3.62 \\
\hline Elevation (m) & 1453 & -4.00 & 1913.00 & 185.03 & 242.56 \\
\hline $\operatorname{Ln}(\mathrm{GDP} p c)(€)$ & 1304 & 7.38 & 11.95 & 9.88 & 0.64 \\
\hline $\begin{array}{l}\text { Population density } \\
\text { (persons per } \mathrm{km}^{2} \text { ) }\end{array}$ & 1415 & 0.60 & 18088.27 & 348.16 & 865.78 \\
\hline $\begin{array}{l}\text { Professional } \\
\text { activities (persons } \\
\text { per } \mathrm{km}^{2} \text { ) }\end{array}$ & 735 & 0.02 & 888.50 & 18.36 & 57.42 \\
\hline $\begin{array}{l}\text { Professional } \\
\text { activities, } \lambda=- \\
7.271 \mathrm{E}-02^{\mathrm{g}}\end{array}$ & 735 & -4.77 & 5.36 & 0.95 & 1.72 \\
\hline $\begin{array}{l}\text { Public } \\
\text { administration } \\
\left(\text { persons per } \mathrm{km}^{2} \text { ) }\right.\end{array}$ & 831 & 0.12 & 3684.83 & 46.12 & 167.39 \\
\hline $\begin{array}{l}\text { Public } \\
\text { administration, } \\
\lambda=5.186 \mathrm{E}-01^{\mathrm{g}}\end{array}$ & 831 & -2.47 & 4.76 & 1.86 & 1.04 \\
\hline $\begin{array}{l}\text { Arts \& } \\
\text { entertainment } \\
\text { (persons per } \mathrm{km}^{2} \text { ) }\end{array}$ & 735 & 0.01 & 377.96 & 9.21 & 25.71 \\
\hline $\begin{array}{l}\text { Arts \& } \\
\text { entertainment, } \\
\lambda=1.392 \mathrm{E}-01^{\mathrm{g}}\end{array}$ & 735 & -5.64 & 4.97 & 0.60 & 1.62 \\
\hline
\end{tabular}

